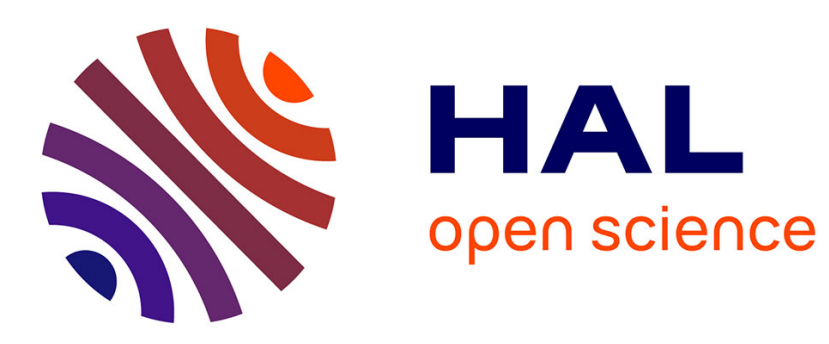

\title{
New cyclic oligothiophenes and their co-oligomers derivatives ofmolecular engineering interest
}

Mohammed Ali Benmensour, Sema Djennane-Bousmaha, Abdou Boucekkine

\section{To cite this version:}

Mohammed Ali Benmensour, Sema Djennane-Bousmaha, Abdou Boucekkine. New cyclic oligothiophenes and their co-oligomers derivatives ofmolecular engineering interest. Synthetic Metals, 2014, 194, pp.182-192. 10.1016/j.synthmet.2014.04.025 . hal-01068875

\section{HAL Id: hal-01068875 \\ https://hal.science/hal-01068875}

Submitted on 6 Oct 2014

HAL is a multi-disciplinary open access archive for the deposit and dissemination of scientific research documents, whether they are published or not. The documents may come from teaching and research institutions in France or abroad, or from public or private research centers.
L'archive ouverte pluridisciplinaire HAL, est destinée au dépôt et à la diffusion de documents scientifiques de niveau recherche, publiés ou non, émanant des établissements d'enseignement et de recherche français ou étrangers, des laboratoires publics ou privés. 
New Cyclic Oligothiophenes And Their Co-Oligomers Derivatives

Of Molecular Engineering Interest

\section{Mohamed BENMENSOUR ${ }^{1}$, Sema DJENNANE-BOUSMAHA ${ }^{1 *}$ and Abdou BOUCEKKINE $^{2 *}$}

1- Laboratoire de Thermodynamique et de Modélisation Moléculaire, Faculté de Chimie, U.S.T.H.B, BP 32 El Alia, 16111 Bab Ezzouar, Alger (Algeria).

2- Institut des Sciences Chimiques de Rennes, UMR 6226 CNRS-Université de Rennes 1, Campus de Beaulieu, 35042 Rennes cedex (France).

* corresponding authors: djennanesema@yahoo.fr; abdou.boucekkine@univ-rennes1.fr

Abstract:

The electronic properties of several series of bridged oligomers and their cooligomers derivatives of five-membered biheterocycles (bithiophene, bipyrrole, bifuran bridged by $\mathrm{CO}$ or $\mathrm{CS}$ group) in their linear and cyclic structures (planar rings and crowns), have been studied using Density Functional Theory (DFT) calculations. The stability of ring forms of bridged oligo(6) biheterocycles is evidenced. Moreover, when replacing the $\mathrm{CO}$ bridging group by the CS one, in all oligomers the HOMO-LUMO energy gap is reduced, due mainly to the strongest stabilization of the LUMO. This energy gap is further reduced with the introduction of bridged bithiophene or bridged bifuran in the cyclic chain of bridged bipyrrole, thus suggesting an improvement of the conductivity properties of such species. The CS bridged co-oligo(3)(bithiophenebipyrrole) and CS bridged co-oligo(3) (bifuran-bipyrrole) seems to be promising candidates for molecular engineering applications.

Keywords: Macrocyclic conducting polymers, polythiophene, polybithiophene, bifuran, bipyrrole, DFT 


\section{INTRODUCTION}


Polyheterocycles, such as polypyrrole, polythiophene, polyaniline and their derivatives, have attracted considerable attention since they can lead to conducting polymer materials. Their conductivity after adequate doping, their good mechanical property and their stability made these compounds candidates for applications in microelectronics and also in various domains of nanotechnology $[1,2]$. New materials based on functionalized heterocycles are actively researched. Experimentally, the synthesis of polyheterocyclic species after functionalization of the monomer or after fusing or bridging monomer units [2-4] constitute a way to access to new polyheterocyclic polymers with enhanced properties. For instance, different polyalkylthiophenes [5] and polybithiophenes exhibiting a low electronic band gap (1.10$1.20 \mathrm{eV}$ ) have been obtained by fusing a benzene and a thiophene ring or by fixing electro-attracting groups on bithiophenes bridged by a substituted $\mathrm{sp}^{2}$ carbon atom [6]. Fusing of different heterocyclic monomers by electrochemical copolymerization was also developed [7-15] in the case of oxidation potentials close to each other. Thus, different copolymers were synthesized electrochemically: pyrrole with bithiophene [9] pyrrole with furan [10] pyrrole with methyl-pyrrole [11, 12], pyrrole with thiophene [13], pyrrole with N-phenyl substituted pyrrole [14]. The electrochemical copolymerization of furan with 3-methylthiophene [15] and with 3-chlorothiophene [16] was also performed: the measurement of the spectro-electrochemical properties of the obtained copolymers shows that they are intermediate between those of their corresponding homopolymers. Moreover the band gap of polyfuran is reduced by incorporation of substituted thiophene units in the polymeric chain. It is also worth noting the synthesis and characterization of new light-emitting copolymers containing 3,4-dialkoxythiophenes [17], and of fluorescent polyheteroaromatic oxadiazoles with alternating electron-donating thiophene and electron-withdrawing oxadiazole units [18] . To our knowledge, the idea of bridging electron-donating and electron-withdrawing groups along a conjugated chain has been initiated by Havinga et al. [19].

The design and synthesis of conjugated copolymers with donor-acceptor architectures for potential applications in microelectronic devices, photovoltaic cells, electrochromics, [20-22] are in continuous development as well as the synthesis and characterization of low-bandgap materials based on benzodithiophene and benzodifuran units [20a] on cyclopentadithiophene (CPDT) [20b], or based on cyclopentathiophene (CPT) as donors and diazole derivatives or triazole derivatives as acceptors [20c]. 
Moreover, since the discovery of fullerenes and carbon nanotubes [23], great interest is focused on systems exhibiting cyclic or tubular structures for which interesting optical, electronic, conducting properties are expected. Mishra et al. [24] describe the synthesis, characterization and properties of mixed macrocycles based on thiophenes and other unsaturated units. Other works highlight interesting electronic and optoelectronic properties of such species [25-30] and of cyclo(n)pyrrole [31]. On the theoretical side, various results have been obtained; in 2012, Shuang Huang et al., using DFT/ MPWB95/6-31G* computations studied the ring size effect on properties of macrocyclic thiophene and pyrrole derivatives [32a]. Then, these authors carried out a ZINDO computational study of the electronic structures, UV-Vis spectra and static second-order nonlinear optical susceptibilities of macrocyclic (trithiophene-diacetylene)n $(n=2,5)$ that showed that macrocyclic thiophene derivatives compounds potentially exhibit large static second-order nonlinear optical susceptibilities [32b]. A previous work focused on 2D-macrocyclo(8)thiophenes [33] which brought to light that there exists a noticeable interaction between $\pi$-orbitals of individual macrocycles in tubular aggregates leading to a decrease of the band gap with the number of units in neutral aggregates. Moreover, oxidized 2D macrocyclic oligothiophenes are able to form tubular aggregates because of $\pi-\pi$ stacking between macrocycles. In the same way, Manuel Garcia et al. [34] investigated theoretically the geometrical and electronic structures as well as electronic properties of Donor-Acceptor Tubular Nanoaggregates of Cyclic Oligocyclo(8)thiophenes and cyclo(8)(3,4dicyanothiophene); they concluded that donoracceptor tubular aggregates could be a promising new class of photovoltaic materials due to a small and adjustable band gap, strong charge separation in the excited state, and high possible mobility of the charge carriers due to their low relaxation energies. Otherwise, cyclic Oligothiophenes [35a] have been studied theoretically at the B3LYP/6-31G(d) level of theory; the results show that HOMO-LUMO gap of cyclooligothiophene is lower than those of corresponding linear oligothiophene. Thus, cyclic oligoheterocycles seem to be promising candidates for applications in electronics, optoelectronics, photovoltaic cells [35b,c].

For our part, we plan to study new co-oligomers of brigded five-membered heterocycles in their linear structure and macrocyclic structures that we expect to be interesting for technological applications. To our knowledge, the sole reported calculations on this kind of species are the ones of Bakhshi and col. [36] who studied the electronic properties and conduction properties of copolymers based on furan and thiophene. The latter studies considered only linear structures, the calculations using ab-initio Hartree-Fock crystal orbital 
method. In a previous work [37], we applied standard B3LYP/6-31G(d) computations to study the structure and electronic properties of linear oligomers based on bithiophene bridged by a $\mathrm{sp}^{2}$ carbon bearing a chalcogen atom $(\mathrm{O}, \mathrm{S}, \mathrm{Se}$ and $\mathrm{Te})$, and of their oligobifuran and oligobipyrrole analogues. An important reduction of the HOMO-LUMO gap was observed for the whole series of biheterocyclic compounds when substituting the extracyclic oxygen atom by a chalcogen atom of higher atomic number. In the present work, several novel series of cooligo five-membered heterocycles, where every biheterocycle (bithiophene, bipyrrole and bifuran) is bridged by $\mathrm{CO}$ or by CS groups, will be considered. The most stable combination of these heterocyclic species, considering different linear and cyclic architectures, will be first studied; then we shall investigate if their electronic and optoelectronic properties are adequate for potential technological applications. Our preliminary design will be based on standard DFT computations.

\section{METHOD OF CALCULATION AND SYSTEMS UNDER CONSIDERATION}

Density Functional Theory (DFT) [38] calculations have been carried out using the B3LYP functional [39] and the standard 6-31G(d) basis set. Another double zeta basis set, namely the LANL2DZ one, also supplemented by polarization functions on heavy atoms, has also been used, because 6-31G(d) is not available for heavy elements. The DFT calculations were carried out using the Gaussian 09 package [40]. The geometry optimizations were followed by vibration frequencies calculations. The calculations have been carried out without any constraint of symmetry.

The structures of the considered unbridged and bridged oligo(6)biheterocycles and cooligo(3) biheterocycles ( $\mathrm{X}$ and $\mathrm{X}^{\prime}=\mathrm{NH}, \mathrm{O}, \mathrm{S}$ and $\mathrm{Y}=\mathrm{S}, \mathrm{O}$ ) in linear and cyclic chains, are given in Figure 1. We have considered the energetically favoured $\alpha-\alpha$, linkage for all linear and cyclic chains. The linear unbridged oligo(6) biheterocyclic model that we considered, is based on a unit constituted by two planar rings, $\alpha-\alpha$ ' linked in such a way that the $\mathrm{X}$ heteroatoms are in trans position (Fig 1a). The same linkage was considered between two bridged biheterocycles in linear bridged oligo (6) biheterocycles and closed bridged oligo (6) biheterocycles ( Figures 1b, 1b', 1c, 1c'). The planar cyclic unbridged and bridged oligo(6) biheterocyclic and co-oligo(3) biheterocyclic models we have considered, are constituted by two units in such a way that the heteroatoms are in a cis position (Figures 1a',1b', 1c'). These 
cyclic planar structures have been our starting point for the geometry optimization of each of the closed oligomers. We found that the optimized final structures could either remain in a planar conformation (a ', b', c') or take a tubular conformation (a ", b", c"). The a" one is a tubular structure where the X heteroatoms are in trans position whereas b" and c" refer to different relative positions of the bridged biheterocyclic units. The structural and electronic properties of each studied oligomer are calculated considering the most stable optimized conformation. The used abbreviation for linear and cyclic unbrigded oligo(6)biheterocycle with 12 rings is $6(\mathrm{H}-\mathrm{H})$ where $\mathrm{H}=(\mathrm{T}, \mathrm{F}, \mathrm{P})$ for respectively thiophene, furan and pyrrole; the $\mathrm{L}$ or $\mathrm{C}$ prefix indicates if the structure is respectively linear or cyclic. The denominations for the bridged linear (b) and cyclic (b',b") bridged oligo (6)biheterocycle are respectively L6 $(\mathrm{HYH})$ and $\mathrm{C} 6(\mathrm{HYH})$ where $\mathrm{Y}=(\mathrm{O}$ or S). For the co-oligomers (c), (c') and (c') the denomination is $\mathrm{L} 3(\mathrm{HYH})\left(\mathrm{H}^{\prime} \mathrm{YH}\right.$ ') and $\mathrm{C} 3(\mathrm{HYH})\left(\mathrm{H}^{\prime} \mathrm{YH}^{\prime}\right)$ where $\mathrm{H} \neq \mathrm{H}^{\prime}=$ (pyrrole or thiophene or furan) and $\mathrm{Y}=(\mathrm{O}, \mathrm{S})$.

For the sake of consistency, the values $\mathrm{n}=6$ for $1 \mathrm{a}, 1 \mathrm{a}$ ', 1a', $1 \mathrm{~b}, 1 \mathrm{~b}$ 'and $1 \mathrm{~b}$ ', and $\mathrm{n}=3$ for $1 \mathrm{c}, 1 \mathrm{c}$ ' and 1c', n being the number of units in the oligomeric chains, have been chosen. 
Linqar structures

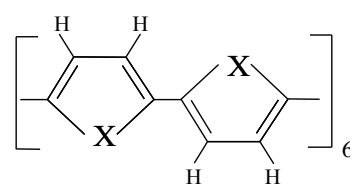

a : L6(H-H)

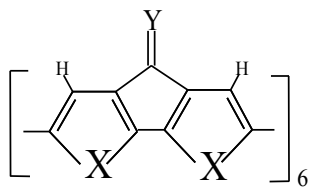

b : L6(HYH)

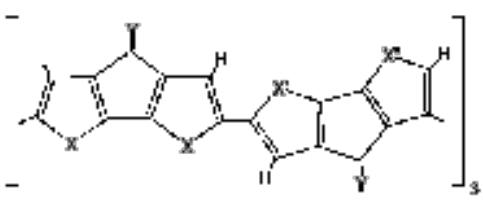

c : L3(HYH)(H'YH') planar ring structures

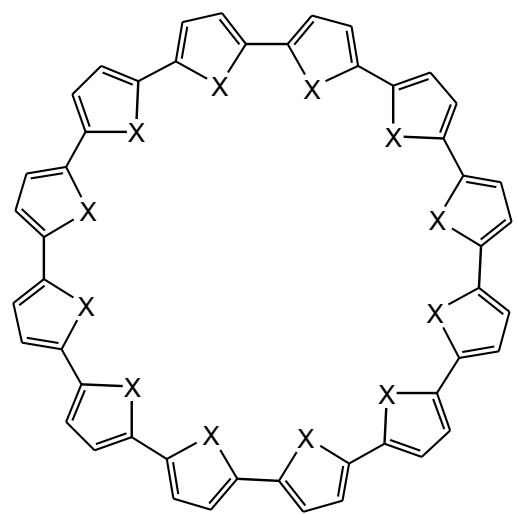

$a^{\prime}: \mathrm{C} 6(\mathrm{H}-\mathrm{H})$ cisoid

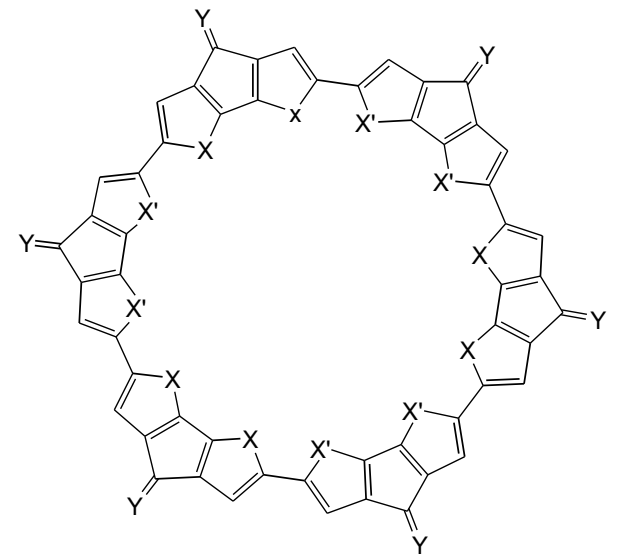

$\mathrm{b}^{\prime}: \mathrm{C} 6(\mathrm{HYH})$

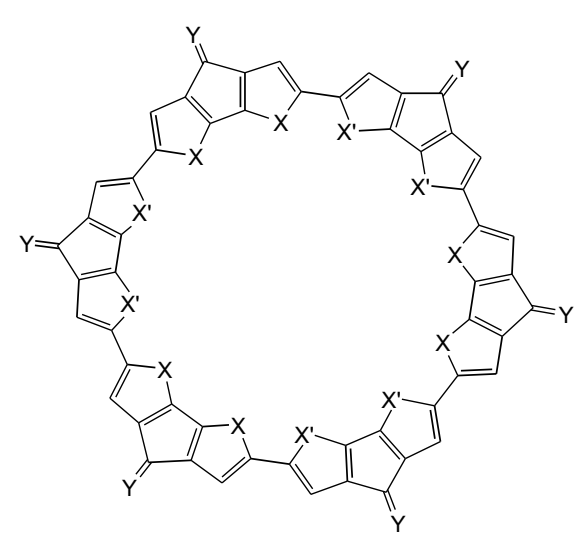

$c^{\prime}: \mathrm{C} 3(\mathrm{HYH})\left(\mathrm{H}^{\prime} \mathrm{YH}^{\prime}\right)$ crown ring structures

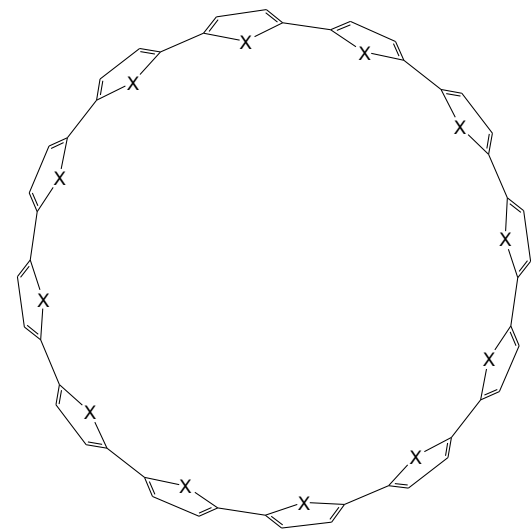

$a^{\prime \prime}$ : $\mathrm{C} 6(\mathrm{H}-\mathrm{H})$ transoid

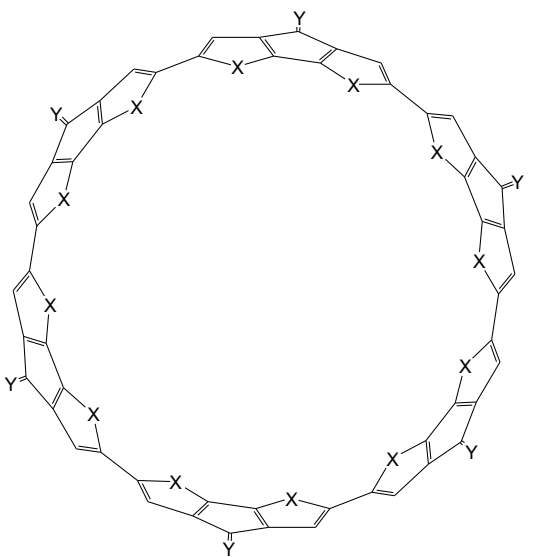

$b^{\prime \prime}: \mathrm{C} 6(\mathrm{HYH})$

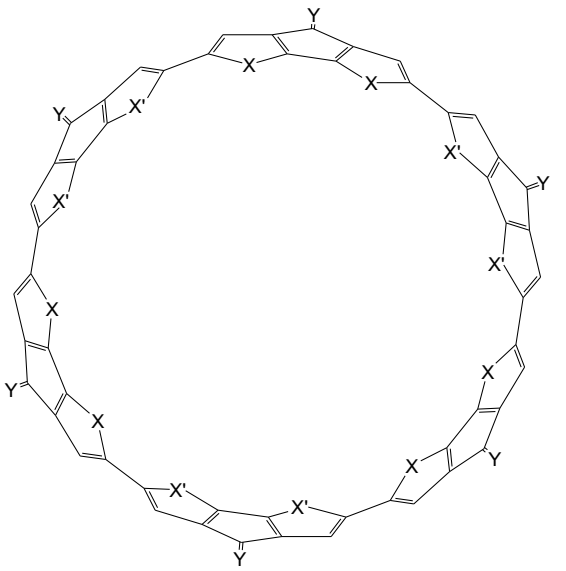

$c^{\prime \prime}: \mathrm{C} 3(\mathrm{HYH})\left(\mathrm{H}^{\prime} \mathrm{YH}^{\prime}\right)$

Fig. 1. Unbridged and bridged oligo(6)biheterocycles and cooligo(3) biheterocycles ( $\mathrm{X}$ and $\mathrm{X}^{\prime}=\mathrm{NH}, \mathrm{O}, \mathrm{S}$ and $\mathrm{Y}=\mathrm{S}, \mathrm{CO})$ in linear and cyclic chains. 


\section{RESULTS AND DISCUSSION}

\section{3-1. UNBRIDGED LINEAR AND CYCLIC OF OLIGO(6) BITHIOPHENE, OF OLIGO(6) BIPYRROLE, AND OF OLIGO(6) BIFURAN}

First, in order to assess the validity of our approach, the structural and electronic properties of well known oligomers of bithiophene, bipyrrole and bifuran, and more specifically oligo(6)biheterocycles in linear (open) and cyclic (ring) chains, have been studied. The optimized values of relevant geometrical parameters are reported in table 1 as well as the drawings of the obtained cyclic structures. All structures have been checked to be ground state ones considering their normal modes of vibration (no imaginary frequency). The optimization of closed structures of cyclic oligo(6)bifuran and cyclic oligo(6)bipyrrole, starting from a planar cisoid ring ( Figure 1a'), led to cyclic transoid conformers of tubular (crown) forms (Fig.1a') (dihedral angles O10-C9-C4-O3 equal to $143^{\circ}$ and $\mathrm{N} 11-\mathrm{C} 10-\mathrm{C} 4-\mathrm{N} 3$ equal to $129^{\circ}$ ) whereas the optimized geometries of cyclic oligo(6)bi thiophene remain cisoid planar (dihedral angles equal to 0.0 or $\sim 180 .^{\circ}$ ). The optimized structures (Table 1 ) in the three cases exhibit only small bond lengths alternation: for example for C6(F-F), the distances C6-C5, C5-C4 and C4-C9 are respectively equal to $c a .1 .43 \AA, 1.38 \AA$ and $1.44 \AA$. Regarding the unbridged linear biheterocycles (Figure 1a), we note that all open structures remain trans planar.

In table 2, we give the HOMO-LUMO energy gap values computed for the most stable structures; they are compared to those already published (Table 2, column Theo.). The experimental values of the polymer energy gaps are also given for comparison (Table 2, column Exp.). In this table the following letters, T, F and $\mathrm{P}$ indicate respectively thiophene, furan and pyrrole oligomers. As expected, we notice that the values of the energy gap decrease with the number $n$ of linked units [37]. For $n=6$ we note that the sole energy gap value obtained for the linear structure species $\mathrm{a}, \mathrm{b}$ and $\mathrm{c}$ (Figure 1) are in good agreement with the gap measured experimentally for polythiophene $(2.3-2.0 \mathrm{eV})$, polyfuran $(2.7 \mathrm{eV})$ and polypyrrole $(3.0 \mathrm{eV})$.The calculated values for linear and cyclic cisoid oligothiophene, i.e. 1.99-2.19 eV are very close to the corresponding experimental value, i.e. 2.0-2.3 eV. We did not find necessary to run calculations for higher linear oligomers in order to get a better estimate of the energy band gap by extrapolation. Such a work has already been done by other 
authors using similar DFT techniques. Our values are similar to the published results of Salztner et al. [41a] who employed the B3P86-30\% functional and CEP-31G(d) and LANL2DZ basis sets. It is worth noting that the different DFT functionals, B3LYP for our part and B3P86-30\% which has been used by Saltzner, give similar energy gaps [41b]. Considering our results obtained using the two basis sets we note that the LANL2DZ(d) gaps are, as expected, very close to the $6-31 G(d)$ values. The differences are lower by about 0.05 $\mathrm{eV}$ for oligo (6) bithiophene and oligo (6) bifuran (linear and cyclic oligomers) and by about $0.5 \mathrm{eV}$ for oligo (6) bipyrrole (linear and cyclic oligomers). The obtained agreement with experiment gives us confidence that the energy band gaps estimations, for the unknown systems which are studied in this paper, are reliable. Our remaining computations will be carried out using the B3LYP functional and the LANL2DZ(d) basis set. 
Table1. B3LYP/ LAN2DZ(d) optimized geometry of cyclic oligo(6)bithiophene (C6(T-T), of cyclic oligo(6)bifuran (C6(F-F)) and of cyclic oligo(6)bipyrrole (C6(P-P)) nn1, n2, n3,n4: atoms numbers

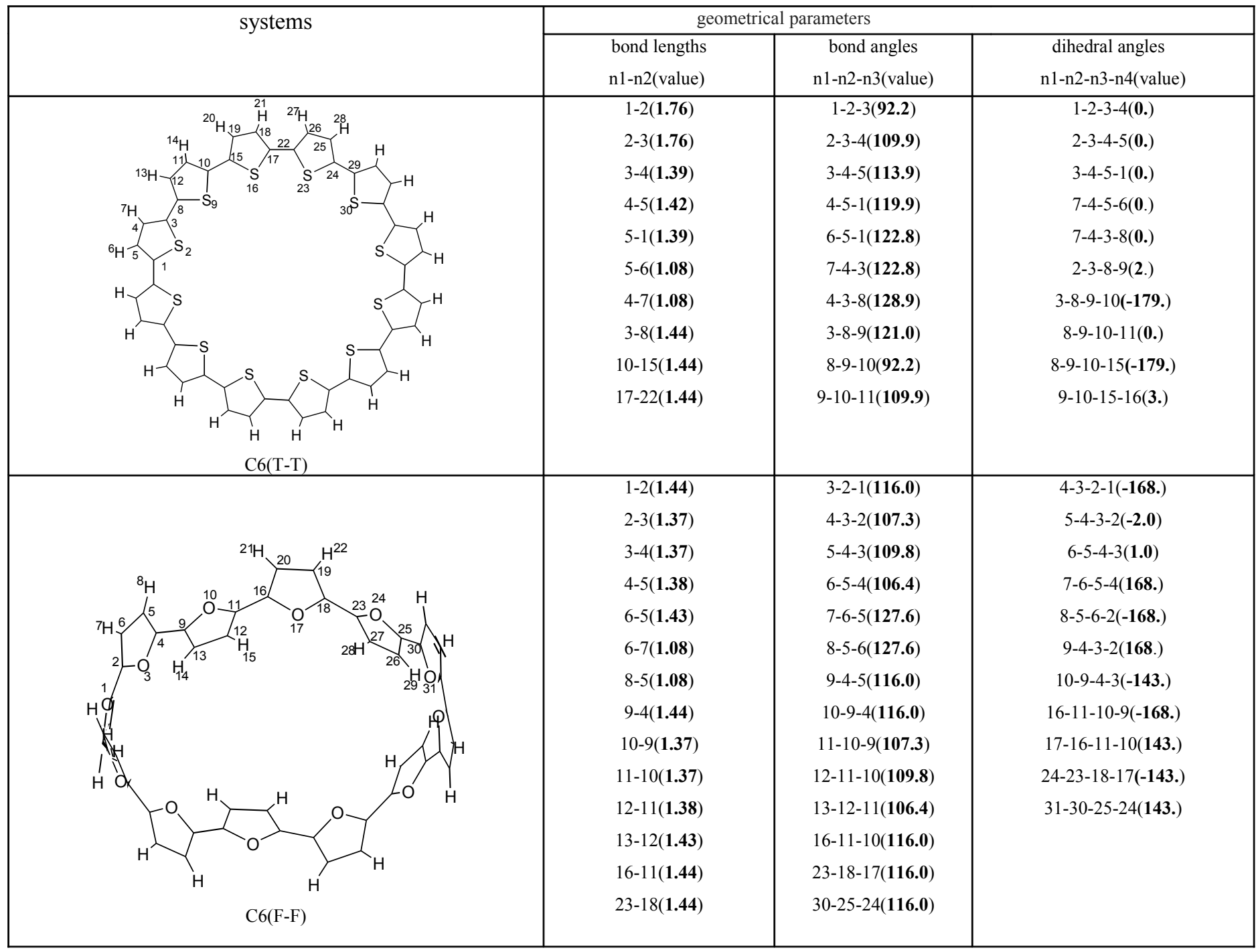




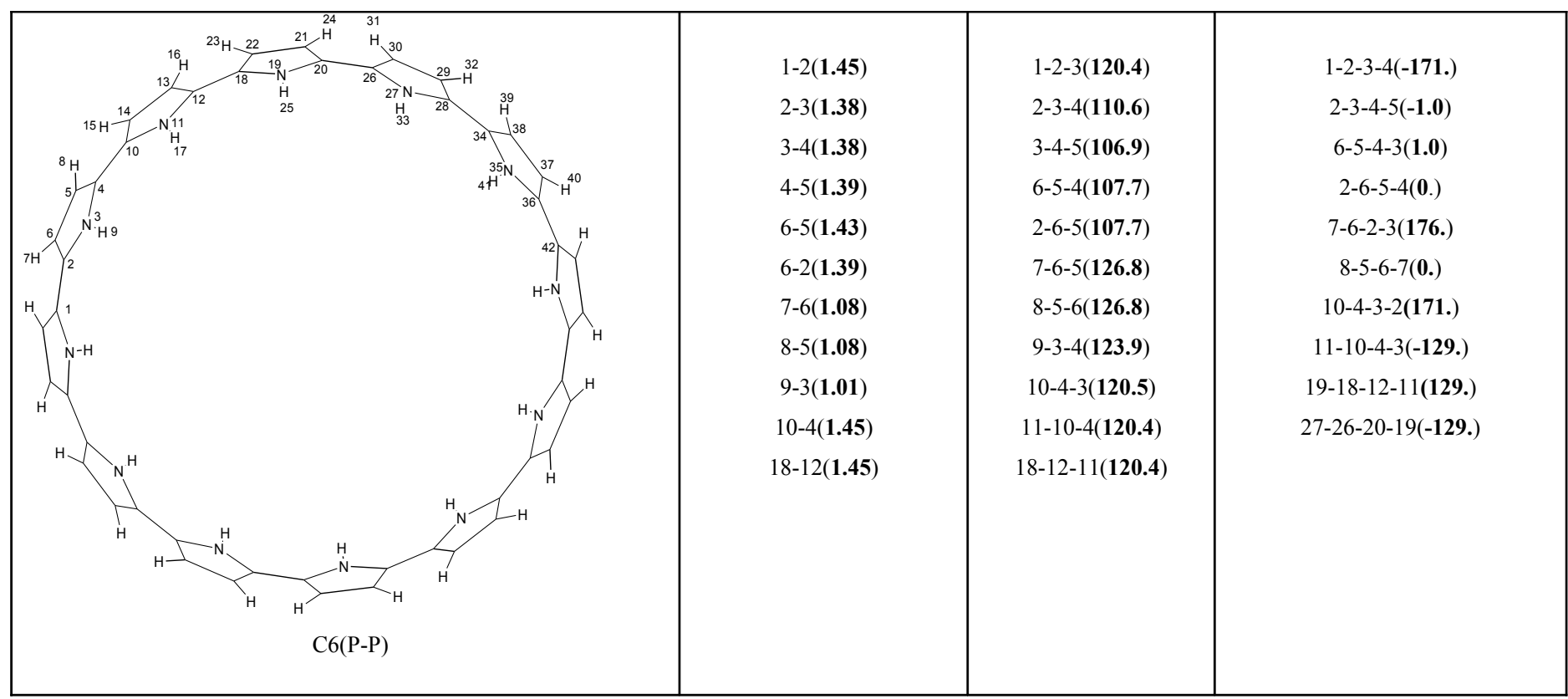

Table 2. B3LYP/LANL2DZ(d) energy gaps (in eV) of oligo (n) biheterocycles (linear and cyclic oligomers)

\begin{tabular}{|c|c|c|c|c|c|c|c|}
\hline \multirow{3}{*}{$\begin{array}{l}\text { Compounds } \\
\text { Ln(H-H) } \\
\mathrm{n}\end{array}$} & \multicolumn{5}{|c|}{ Basis set } & \multirow{3}{*}{$\begin{array}{l}\text { Theo. } \\
\text { [39] } \\
3\end{array}$} & \multirow{3}{*}{$\begin{array}{l}\text { Exp. } \\
\frac{[2,3,6]}{\circ} \\
\circ\end{array}$} \\
\hline & \multicolumn{4}{|c|}{$6-31 \mathrm{G}^{*}$} & LANL2DZ(d) & & \\
\hline & $1^{\mathrm{a}}$ & $2^{\mathrm{a}}$ & $3^{\mathrm{a}}$ & 6 & 6 & & \\
\hline $\operatorname{Ln}(\mathrm{T}-\mathrm{T})$ & 4.23 & 3.08 & 2.50 & 2.23 & 2.19 & $2.30^{\mathrm{b}} 2.21^{\mathrm{c}}$ & $2.3-2.0$ \\
\hline $\begin{array}{c}\mathrm{Cn}(\mathrm{T}-\mathrm{T}) \\
\text { cisoid }\end{array}$ & - & - & - & 1.95 & 1.99 & & \\
\hline $\operatorname{Ln}(\mathrm{F}-\mathrm{F})$ & 4.67 & 4.09 & 2.81 & 2.60 & 2.56 & & \\
\hline $\begin{array}{l}\mathrm{Cn}(\mathrm{F}-\mathrm{F}) \\
\text { transoid }\end{array}$ & - & - & - & 2.82 & 2.86 & 2.67 & 2.7 \\
\hline $\operatorname{Ln}(\mathrm{P}-\mathrm{P})$ & 4.90 & 4.27 & 3.38 & 3.45 & 2.98 & & \\
\hline $\begin{array}{l}\mathrm{Cn}(\mathrm{P}-\mathrm{P}) \\
\text { transoid }\end{array}$ & & & & 3.53 & 3.77 & 3.16 & 3.0 \\
\hline
\end{tabular}

a:Values from a previous work [37]

b: CEP-31G(d) basis set [41]

c: B3P86-30\% functional and LANL2DZ basis set [41] 


\section{3-2. DFT RESULTS FOR OLIGO (6) BITHIOPHENE, BIPYRROLE AND BIFURAN BRIDGED BY CO AND CS GROUPS IN LINEAR AND CYCLIC STRUCTURE}

In order to study the effect of bridging and linking on the electronic properties, we considered first the oligo(6) bridged biheterocycles. The values of the energy of the HOMO and LUMO, and the energy gap computed after a full geometry optimization, of the different bridged biheterocyclic compounds are reported in Tables 2, 3 and 4 respectively for oligo(6) bridged bithiophene, oligo(6) bridged bifuran and oligo(6) bridged bipyrrole derivatives, in linear structures (noted respectively L6(TYT), L6(FYF), L6(PYP)) and in cyclic structures (noted respectively $\mathrm{C6}(\mathrm{TYT}), \mathrm{C} 6(\mathrm{PYP}), \mathrm{C} 6(\mathrm{FYF}))$. $\mathrm{Y}$ is either the $\mathrm{O}$ or $\mathrm{S}$ atom of the bridging group CY.

For comparison the computed values for the most stable structures of unbridged oligo(6)

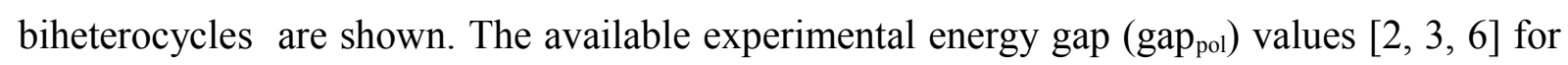
the polymers are also given.

Table 3. B3LYP/LANL2DZ(d) computed energies $(\mathrm{eV})$ of linear and cyclic oligo(6) bridged bithiophene derivatives (Figure 1)

\begin{tabular}{|c|l|l|l|l|}
\hline \multirow{2}{*}{$\begin{array}{c}\text { bridged } \\
\text { oligo(6)bithiophene }\end{array}$} & \multicolumn{3}{|l|}{ B3LYP/ LANL2DZ(d) } & $\begin{array}{l}\text { Exp } \\
{[2,3,6]}\end{array}$ \\
\cline { 2 - 5 } & $-\varepsilon_{\text {HOMO }}$ & $-\varepsilon_{\text {LUMO }}$ & Gap & Gap $_{\text {pol }}$ \\
\hline L6(T-T) & 4.80 & 2.61 & 2.19 & $2.3-2.0$ \\
\hline L6(TOT) & 5.15 & 3.40 & 1.75 & 1.2 \\
\hline L6(TST) & 5.05 & 3.70 & 1.35 & \\
\hline C6(T-T) & 4.61 & 2.62 & 1.99 & \\
\hline C6(TOT) & 4.76 & 3.92 & 0.84 & \\
\hline C6(TST) & 4.71 & 3.91 & 0.80 & \\
\hline & & & & \\
\hline
\end{tabular}


${ }^{\text {a }}$ L6(T-T): linear unbridged oligo(6)bithiophene; C6(T-T): cyclic unbridged oligo(6)bithiophene

L6(TYT): linear bridged oligo(6)bithiophene; C6(TYT): cyclic bridged oligo (6)bithiophene with Y= ( $\mathrm{O}$ or $\mathrm{S})$.

Table 4. B3LYP/LANL2DZ(d) computed energies (eV) of linear and cyclic oligo(6) bridged bifuran derivatives (Figure 1)

\begin{tabular}{|c|l|l|l|l|}
\hline \multirow{2}{*}{$\begin{array}{c}\text { bridged } \\
\text { oligo(6) bifuran }\end{array}$} & \multicolumn{3}{|l|}{ B3LYP/ LANL2DZ(d) } & $\begin{array}{l}\text { Exp } \\
{[2,3,6]}\end{array}$ \\
\hline & $-\varepsilon_{\text {HOMO }}$ & $-\varepsilon_{\text {LUMO }}$ & Gap & Gap $_{\text {pol }}$ \\
\hline L6(F-F) & 4.61 & 2.05 & 2.56 & 2.7 \\
\hline L6(FOF) & 4.96 & 3.20 & 1.76 & \\
\hline L6(FSF) & 4.83 & 3.62 & 1.21 & \\
\hline C6(F-F) & 4.71 & 1.85 & 2.86 & \\
\hline C6(FOF) & 4.89 & 3.33 & 1.56 & \\
\hline C6(FSF) & 4.76 & 3.70 & 1.06 & \\
\hline & & & & \\
\hline
\end{tabular}

${ }^{\text {a }}$ L6(F-F): linear unbridged oligo(6)bifuran; C6(F-F): cyclic unbridged oligo (6) bifuran.

L6(FYF): linear bridged oligo(6) bifuran; C6(FYF): cyclic bridged oligo (6) bifuran with Y=( $\mathrm{O}$ or S). 
Table 5. B3LYP/LANL2DZ(d) computed energies $(\mathrm{eV})$ of linear and cyclic bridged oligo (6) bipyrrole derivatives (Figure 1)

\begin{tabular}{|c|l|l|l|l|}
\hline \multirow{2}{*}{$\begin{array}{c}\text { bridged } \\
\text { oligo(6)bipyrrole }\end{array}$} & \multicolumn{3}{|l|}{ B3LYP/ LANL2DZ(d) } & $\begin{array}{l}\text { Exp } \\
{[2,3,6]}\end{array}$ \\
\hline & $-\varepsilon_{\text {HOMO }}$ & $-\varepsilon_{\text {LUMO }}$ & Gap & Gap pol \\
\hline L6(P-P) & 4.04 & 1.06 & 2.98 & 3.0 \\
\hline L6(POP) & 4.64 & 2.26 & 2.38 & \\
\hline L6(PSP) & 4.60 & 2.91 & 1.69 & \\
\hline C6(P-P)trans & 4.51 & 0.74 & 3.77 & \\
\hline C6(POP) & 5.07 & 2.31 & 2.76 & \\
\hline C6(PSP) & 5.05 & 3.00 & 2.05 & \\
\hline & & & & \\
\hline
\end{tabular}

${ }^{\text {a }}$ L6(P-P): linear unbridged oligo(6) bipyrrole; C6(P-P): cyclic unbridged oligo (6) bipyrrole.

L6(PYP): linear bridged oligo(6) bipyrrole; C6(PYP): cyclic bridged oligo (6) bipyrrole with Y=( O or $\mathrm{S})$.

It is not possible to compare our results to those obtained by Saltzner and Coll. [41] for similar species, because they only studied the case $n=1$ (corresponding to 2 heterocyclic rings). Obviously the HOMO-LUMO gaps that we computed for high oligomers $(n=6)$ are much lower than those of Saltzner.

It is worth noting that substituting by $\mathrm{O}$ or $\mathrm{S}$ the $\mathrm{sp}^{2}$ carbon atom of the bridge reduces the 
HOMO-LUMO gap in all cases. This effect is more pronounced for the cyclic structures than for the corresponding open structures. For example the energy gap of cyclic unbridged oligo(6) bithiophene i.e. $1.99 \mathrm{eV}$, decreases to $0.84 \mathrm{eV}$ and $0.80 \mathrm{eV}$ after bridging respectively by the $\mathrm{CO}$ and $\mathrm{CS}$ groups. The energy gaps of cyclic $\mathrm{CO}$ bridged dithiophene derivatives $(0.84 \mathrm{eV})$ are lower than those of cyclic $\mathrm{CO}$ bridged difuran derivatives $(1.56 \mathrm{eV})$ which are themselves lower than those of cyclic CO bridged bipyrrole derivatives $(2.76 \mathrm{eV})$. As pointed out in our previous work [38] on linear structures, we similarly obtain for the cyclic structures a more important reduction of the energy gap with the CS bridging group than with the $\mathrm{CO}$ one. The gap values are respectively $0.80 \mathrm{eV}, 1.06 \mathrm{eV}, 2.05 \mathrm{eV}$ for $\mathrm{CS}$ bridged dithiophene derivatives, cyclic CS bridged difuran derivatives, and cyclic CS bridged bipyrrole derivatives. Besides, as it can be seen in Tables 2-4, the HOMO energy obtained after bridging remains relatively constant independently of the CO or CS moiety for both the linear and cyclic structures. On the contrary, an important decrease of the energy of the LUMO for all compounds after such substitution can be noticed. This result can be easily rationalized considering the frontier MOs of the unbridged and the bridged cyclo oligo(6) biheterocycles which are displayed on figures 2-1, 2-2, 2-3. Indeed, these species exhibit practically the same HOMO. In contrast, the LUMO depends on the nature of the bridging group thus explaining the observed energy lowering.

\section{3-3. DFT CALCULATIONS ON LINEAR AND CYCLIC STRUCTURES OF CO-OLIGO} (3) BRIDGED BITHIOPHENE, BIPYRROLE AND BIFURAN DERIVATIVES

The study is now extended to linear and ring structures of co-oligo (3) bridged bithiophene, bipyrrole and bifuran derivatives, noted respectively L3((HYH)(H'YH')) and C3((HYH) $\left.\left(\mathrm{H}^{\prime} \mathrm{YH}^{\prime}\right)\right)$ where $\mathrm{H} \neq \mathrm{H}^{\prime}$ are $\mathrm{T}, \mathrm{F}, \mathrm{P}$ for respectively thiophene, furan and pyrrole; $\mathrm{Y}$ is $\mathrm{O}$ or $\mathrm{S}$ atom of the bridging group $\mathrm{CY}$.

The co-oligomers are obtained by considering the periodical sequence of two different bridged biheterocycles (HYH) and (H'YH'). All cases are considered. The purpose of this study is to investigate the effect of the substitution of a bridged biheterocycle (HYH) by another one (H'YH') aiming to find a suitable combination allowing potential applications. The computed values at the B3LYP/LANL2DZ(d) level of theory are reported in Table 6 and 7 respectively for the linear and cyclic forms; the results for the reference oligomers are also 
given.

It can be noticed for the linear chains (Table 6) that (i) the energy gap values obtained for the bridged co-oligomers are all lower than those of their corresponding reference oligomers. This suggests that the properties of conductivity of co-oligomers could be higher than that of corresponding oligomers; (ii)when the bridging group is $\mathrm{CO}$, the substitution of bridged bipyrrole by bridged bifuran or by bridged bithiophene does not affect the energy gap: the value obtained for all co-oligomers is practically the same (between 1.66 and $1.68 \mathrm{eV}$ ). (iii) on the contrary, we notice that this effect is significant when the bridging group is CS: the energy gap of the oligo(6) bipyrrole L6 (PYP) passes from $1.58 \mathrm{eV}$ to $1.14 \mathrm{eV}$ (L3)(PYP) (TYT))) and $1.02 \mathrm{eV}(\mathrm{L} 3(\mathrm{PYP})(\mathrm{FYF}))$ ) when a bridged bipyrrole is replaced, respectively, by a bridged bithiophene and bridged bifuran.

In Figure 3, we display the frontier MO diagrams of these species. We notice that: (i) the HOMO of L3 (TST) and of L3(PSP) are $\pi$ MOs fully delocalized over the rings and do not involve the CS group. (ii) The LUMO of L3 (TST) exhibits a strong contribution of the three bridging groups CS and of the sulfur atoms of the rings. On the contrary, the LUMO of L3( PSP) which is of higher energy (-2.73 eV vs. $-3.54 \mathrm{eV}$ for L3(TST)) is mostly localized on one central CS group. (iii) the $\pi^{*}$ LUMO of the co-oligomers is localized on the TST moieties with an almost zero contribution of the PSP fragments; this results first to a LUMO energy of the co-oligomer similar to L3(TST) ca. $-3.55 \mathrm{eV}$, and secondly to a significant lowering of the LUMO energy of L3(TSTPSP) relatively to L3(PSP); (iv) The smallest gap value $(1.02 \mathrm{eV})$ is obtained for the combination L3 (PSPFSF) due to stabilization of the LUMO after introduction of the FSF sequence within the oligo (6) bridged bipyrrole. 
Table 6. B3LYP/ LANL2DZ(d) computed energies (eV) of the brigded oligo(6) and cooligo(3) bithiophene, bipyrrole and bifuran derivatives (linear structures)

\begin{tabular}{|c|c|c|c|}
\hline compounds & Y & $\mathrm{CO}$ & CS \\
\hline \multirow{3}{*}{ L6 (PYP) } & $-\varepsilon_{\mathrm{HOMO}}$ & 4.59 & 4.54 \\
\hline & $-\varepsilon_{\text {LUMO }}$ & 2.35 & 2.96 \\
\hline & gap & 2.24 & 1.58 \\
\hline \multirow{3}{*}{ L6(FYF) } & $-\varepsilon_{\mathrm{HOMO}}$ & 5.50 & 5.33 \\
\hline & $-\varepsilon_{\text {LUMO }}$ & 3.48 & 3.86 \\
\hline & gap & 2.02 & 1.47 \\
\hline \multirow{3}{*}{ L6(TYT) } & $-\varepsilon_{\mathrm{HOMO}}$ & 5.44 & 5.31 \\
\hline & $-\varepsilon_{\text {LUMO }}$ & 3.61 & 3.89 \\
\hline & gap & $1.83(1.93)^{2}$ & 1.42 \\
\hline \multirow{3}{*}{ L3( PYP)(FYF)) } & $-\varepsilon_{\mathrm{HOMO}}$ & 4.64 & 4.56 \\
\hline & $-\varepsilon_{\mathrm{LUMO}}$ & 2.98 & 3.54 \\
\hline & gap & 1.66 & 1.02 \\
\hline \multirow{3}{*}{ L3((PYP)(TYT)) } & $-\varepsilon_{\mathrm{HOMO}}$ & 4.75 & 4.69 \\
\hline & $-\varepsilon_{\mathrm{LUMO}}$ & 3.09 & 3.55 \\
\hline & gap & 1.66 & 1.14 \\
\hline \multirow{3}{*}{ L3((FYF)(TYT)) } & $-\varepsilon_{\mathrm{HOMO}}$ & 5.00 & 4.89 \\
\hline & $-\varepsilon_{\text {LUMO }}$ & 3.32 & 3.66 \\
\hline & gap & 1.68 & 1.23 \\
\hline
\end{tabular}

From the results of Table 7 for the cyclic brigded oligo(6) and co-oligo(3) bithiophene, bipyrrole and bifuran derivatives, it can be seen that: (i) substituting in the sequence [(FYF) (FYF)] a FYF fragment by a TYT fragment results in a small change of the value of the energy gap, i.e. from $1.56 \mathrm{eV}$ to 1.58 (when $\mathrm{Y}=\mathrm{CO}$ ) and 1.06 to $1.16 \mathrm{eV}$ (where $\mathrm{Y}=\mathrm{CS}$ ) in the C6 (FYF) case; (ii) the gap values obtained for C3 ((TYT) (FYF)) co-oligomer are higher than those of the same unit oligomers C6 (TYT) and C6 (FYF); (iii) substitution in the sequence [(PYP) (PYP)] of a bridged bipyrrole PYP unit by a bridged bifuran FYF decreases the energy gap from $2.76 \mathrm{eV}(\mathrm{C} 6(\mathrm{PYP})$ value) to $1.52 \mathrm{eV}$ (when $\mathrm{Y}=\mathrm{CO}$ ), and from 2.05 to 
$0.94 \mathrm{eV}$ (when Y = CS). The values obtained for C3 ((PYP) (FYF)) co-oligomer are slightly lower than those of C6 (FYF): 1.56 and $1.06 \mathrm{eV}$ respectively for $\mathrm{CO}$ and $\mathrm{CS}$ bridging; (iv) substituting in the sequence [(PYP) (PYP)] a fragment PYP by a bridged bithiophene TYT decreases the energy gap of the C6 (PYP) of 2.76 to $1.66 \mathrm{eV}$ (when Y $=\mathrm{CO}$ ), and 2.05 to 1.17 $\mathrm{eV}$ (when $\mathrm{Y}=\mathrm{CS}$ ). The gap values obtained for the co-oligomer C3 ((PYP) (TYT)) are intermediate between those of the C6 (PYP) and C6 (TYT) independently of the bridging group nature.

Table 7. B3LYP/LANL2DZ(d) computed energies (eV) of the bridged oligo(6) and cooligo(3) bithiophene, bipyrrole and bifuran derivatives (cyclic structures)_

\begin{tabular}{|c|c|c|c|}
\hline compounds & Y & $\mathrm{CO}$ & $\mathrm{CS}$ \\
\hline \multirow{3}{*}{ C6 (PYP) } & $-\varepsilon_{\mathrm{HOMO}}$ & 5.07 & 5.05 \\
\hline & $-\varepsilon_{\text {LUMO }}$ & 2.31 & 3.00 \\
\hline & gap* & 2.76 & 2.05 \\
\hline \multirow{3}{*}{ C6(FYF) } & $-\varepsilon_{\mathrm{HOMO}}$ & 4.89 & 4.76 \\
\hline & $-\varepsilon_{\text {LUMO }}$ & 3.33 & 3.70 \\
\hline & gap & 1.56 & 1.06 \\
\hline \multirow{3}{*}{ C6(TYT) } & $-\varepsilon_{\mathrm{HOMO}}$ & 4.66 & 4.71 \\
\hline & $-\varepsilon_{\text {LUMO }}$ & 3.92 & 3.91 \\
\hline & gap & 0.74 & 0.80 \\
\hline \multirow{3}{*}{ C3( PYP)(FYF)) } & $-\varepsilon_{\mathrm{HOMO}}$ & 4.68 & 4.60 \\
\hline & $-\varepsilon_{\text {LUMO }}$ & 3.15 & 3.66 \\
\hline & gap & 1.52 & 0.94 \\
\hline \multirow{3}{*}{ C3((PYP)(TYT)) } & $-\varepsilon_{\mathrm{HOMO}}$ & 5.00 & 4.94 \\
\hline & $-\varepsilon_{\text {LUMO }}$ & 3.34 & 3.77 \\
\hline & gap & 1.66 & 1.17 \\
\hline \multirow{3}{*}{ C3((FYF)(TYT)) } & $-\varepsilon_{\text {НОмо }}$ & 5.03 & 4.90 \\
\hline & $-\varepsilon_{\text {LUMO }}$ & 3.45 & 3.74 \\
\hline & gap & 1.58 & 1.16 \\
\hline
\end{tabular}

In Figure 3-2 and 3-3 are given respectively the frontier MO diagrams of the cyclo CS bridged co-oligo(3)(bithiophene-bipyrrole), noted C3((TST)(PSP)) and cyclo CS bridged cooligo(3)(bifuran-bipyrrole) noted C3((FSF)(PSP)). The frontier MO diagrams of cyclo oligo(6)biheterocycles noted C3((TST)(TST)), C3((PSP)(PSP)), C3((FSF)(FSF)) which are the basic oligomers before co-oligomerization are also given. Orbital analysis for C3((TST) 
(PSP)) shows that: (i) the HOMO of C3 ((TST)(TST)), of C3 ((TST)(FSF)) and of C3 ((PSP) (PSP)) are $\pi$ MOs fully delocalized over the rings and do not involve the CS group. (ii) the LUMO of C3 ((TST)(TST)) is a $\pi^{*}$ MO fully delocalized over the rings and does not involve the CS group (iii) the LUMO of C3 ((PSP)(PSP)) exhibits a strong contribution of the six bridging groups CS (iv) the HOMO of C3 ((TST)(PSP)), is a $\pi$ MO fully delocalized over the rings which does not involve neither the CS group nor heteroatoms of ring. The $\pi^{*}$ LUMO of the co-oligomers expands mainly over three TST moieties with an almost zero contribution of the PSP fragments; this results in a significant lowering of the LUMO energy of $\mathrm{C} 3((\mathrm{TST})(\mathrm{PSP}))$ relatively to $\mathrm{C} 3((\mathrm{PSP})(\mathrm{PSP}))$; (iv) the gap value (1.17 eV) obtained for the combination $\mathrm{C} 3$ ((TST)(PSP)) is closer to the $\mathrm{C} 3$ ((TST)(TST ) one, i.e. $0.80 \mathrm{eV}$ rather than the $\mathrm{C} 3$ ((PSP)(PSP)) values equal to $2.05 \mathrm{eV}$.

\section{CONCLUSION}

A series of unbridged and bridged oligomers of five-membered heterocycles (bithiophene, bipyrrole, bifuran bridged by $\mathrm{CO}$ or by $\mathrm{CS}$ group, exhibiting a linear or ring-shaped macrocyclic structure has been studied by means of standard B3LYP/LANL2DZ(d) DFT computations. In particular, the effects of bridging and co-oligomer linking on the structural and electronic properties of the oligo (6) bridged biheterocycles, have been investigated. Different ring structures can be obtained. The optimization of closed structures starting from planar cyclic cisoid oligo(6)bifuran and cyclic oligo(6)bipyrrole leads to cyclic transoïd conformers corresponding to tubular (crown) forms whereas the optimized structure of cyclic oligo(6)bithiophene remain cisoid planar. The full optimizations of the unbridged linear biheterocycles, starting from a planar geometry, show that all open structures remain trans planar. The ring structures exhibit lower HOMO-LUMO gaps than the linear ones.

We considered the bridged oligo(6)bithiophene, the bridged oligo(6)bifuran, and the bridged oligo(6)bipyrrole, as well as the bridged co-oligo(3)(bithiophene-bipyrrole) and bridged cooligo(3)(bithiophene-bifuran) obtained replacing three bridged bithiophene by respectively three bridged bipyrrole or by three bridged bifuran considering different linking modes (leading to a linear or ring structure). The bridged co-oligo(3)(bifuran-bipyrrole) resulting 
from the substitution of three bridged bifuran by respectively three bridged bipyrrole as also been studied. Interestingly, it appears that for the linear chains, a significant decrease of the gap value after replacement of bridged biheterocycle by another can be obtained; the gap values obtained for the bridged co-oligomers are all lower than those of the corresponding reference oligomers. This effect is significant when the bridging group is CS. The energy gap lowering is due to the energy decrease of the LUMO of the considered species. This is well rationalized considering the frontier MO diagrams of the studied species.

For the ring-shaped chains, the cooligomerization of cyclo bridged oligo(6)bipyrrole with cyclo bridged oligo(6)bifuran or cyclo bridged oligo(6)bithiophene leads to a decrease of the computed energy gap of the cyclo bridged oligo(6)bipyrrole. The values obtained for the cyclo bridged co-oligo(3)(bithiophene-bipyrrole) are intermediate between those of the cyclo bridged oligo(6)bipyrrole and cyclo bridged oligo(6)bithiophene regardless of bridging group. The values obtained for the cyclo bridged co-oligo(3)(bifuran-bipyrrole) are slightly lower than those of cyclo bridged oligo(6)bifuran .

Our calculations suggest that the properties of conductivity of bridged linear and cyclic cooligomer should be better than that of corresponding basis bridged oligomers. Among them, the cyclo bridged co-oligo(3)(bithiophene-bipyrrole) and the cyclo bridged co-oligo(3) (bifuran-bipyrrole) seem to be good candidates for potential technological applications.

\section{Acknowledgements}

GENCI-IDRIS-CINES (Grants Nos. 2012-080649 and 2013-080649) are acknowledged for a grant of computational time.

\section{REFERENCES}

[1] T.A. Skotheim, (ed.), Handbook of Conducting Polymers, Dekker: NY (1998)

[2] J. Roncali, Chem. Rev. 92 (1992) 711.

[3] a. J. Roncali, Chem. Rev. 97 (1997) 173;

b. J. Roncali, C. Thobie-Gautier, H. Brisset, M. Jubault, A. Gorgues, J. Chim. Phys. 92 
(1995) 767;

c. J. Roncali, H. Brisset, C. Thobie-Gautier, M. Jubault, A. Gorgues, J. Chim. Phys. 92 (1995) 771;

d. H. Brisset, C. Thobie-Gautier, A. Gorgues, M. Jubault, J. Roncali, J. Chem. Soc., Chem. Commun. (1994) 1305.

[4] F. Wudl, M. Kobayashi, A. J. Heeger, J. Org. Chem. 49 (1984) 3382.

[5] L. Lemaire, R. Garreau, F. Garnier, J. Roncali, New J. Chem. 11 ( 1987 ) 10.

[6 ] a. T.M. Lambert, J.P. Ferraris, J. Chem. Soc. Chem. Commun. (1991) 752 ;

b. J.P. Ferraris, T.M. Lambert, J. Chem. Soc. Chem. Commun. (1991) 1268.

[7] H. Laborde, J.M. Leger, C. Lamy, F. Garnier, A. Yassar, J. Appl. Electrochem. 20 (1990) 524.

[8] E. M.Peters, J.D. VanDyke, J. Polym.Sci, Part A: Polym.Chem. 29 (1991) 1379.

[9] X. D. Dang, C. M. Intelmann, U. Rammelt, W. Plieth, J. Solid State Electrochem. 810 (2004) 727.

[10] X.B. Wan, W. Zhang, S. Jin, G. Xue, Q.D.You, B. Che, J. Electroanal. Chem. 470 (1999) 23.

[11] P. Novak, W.Vielstich, J. Electroanal.Chem. 300 (1991) 99.

[12] M. Nishizawa, T. Sawagushi, T. Matsue, I. Uchida, Synth. Met. 45 (1991) 241.

[13] S. Kuwabata, S. Ito, H.Yoneyama, J. Electrochem. Soc. 135 (1988) 1691.

[14] J.R. Reynolds, P.A. Poropatic, R.L. Toyooka, Macromolecules 20 (1987) 958.

[15] L. Li, W. Chen, N. Xu, Z. Xiao, G. Xue, J. Mater. Sci. 39 (2004) 2395.

[16] F. Alaakhras, R. Holze, J. Solid State Electrochem. 12 (2008) 81.

[17] D. Udayakumar, A.V. Adhikari, Synth. Met. 156 (2006) 1168.

[18] S.C. Ng, M. Ding, H.S.O. Chan, W.L. Yu, Macromol. Chem. Phys. 202 (2001) 8.

[19] a. E.E. Havinga, W. ten Hoeve, H. Wynberg, Polym. Bull. 29 ( 1992) 119;

b. E.E. Havinga, W. ten Hoeve, H. Wynberg, Synth. Met. 55 ( 1993) 299.

[20] a. Y. Zhang, L. Gao, C. He, Q. Sun, Y. Li, Polym. Chem. 4 (2013) 1474;

b. A. Bedi, S.P. Senanayak, S. Das, K.S. Narayan, S.S. Zade, Polym. Chem. 3 (2012) 1453 ;

c. P. Willot, L. De Cremer, G. Koeckelberghs, Macromol. Chem. and Phys. 213 (2012) 1216.

[21] S. Sato, K. Hashimoto, K. Tajima, Synth. Met. 161 ( 2011) 1289. 
[22] a. K. Navamani, G. Saranya, P. Kolandaivel, K. Senthilkumar, Phys. Chem. Chem. Phys. 15 (2013) 17947;

b. P. Sonar, E. L. Williams, S. P. Singh, S. Manzhos, A. Dodabalapur, Phys. Chem. Chem. Phys. 15 (2013) 17064;

c. T.-J. Ha, P. Sonar, A. Dodabalapur, Phys. Chem. Chem. Phys.15 (2013) 9735;

d. M.G. Manjunatha, A.V. Adhikari, P.K. Hegde, Eur. Polym. J. 45 (2009) 3763;

e. X. Sun, Y. Liu, X. Xu, G. Yu, S. Chen, W. Qiu, Y. Ma, Z. Zhao, D. Zhu, Synth. Met. 156 (2006) 1174.

[23] H.W. Kroto, J.R. Heath, S.C. O'Brien, R.F. Curl, R.E. Smalley, Nature 318 (1985) 162.

[24] A. Mishra, C.-Q. Ma, P. Bäuerle, Chem. Rev. 109 (2009) 1141.

[25] G. Fuhrmann, T. Debaerdemaeker, P. Bäuerle, Chem. commun. (2003) 948.

[26] a. J. Krömer, I. Rios-Carreras, G. Fuhrmann, C. Musch, M. Wunderlin, T. Debaerdemaeker, E. Mena-Osteritz, P. Bauerle, Angew. Chem. 112 (2000) 3623;

b. J. Krömer, I. Rios-Carreras, G. Fuhrmann, C. Musch, M. Wunderlin, T. Debaerdemaeker, E.Mena-Osteritz, P. Bauerle, Angew. Chem. Int. Ed. 39 (2000) 3481;

c. E. Mena-Osteritz, P. Bäuerle, Adv. Mater. 13 (2001) 243;

d. G. Fuhrmann, P. Bäuerle, Chem. Commun. (2003) 926;

e. P. Bäuerle, T. Fischer, B. Bidlingmeier, J.P. Rabe, A. Stabel, Angew. Chem. Int. Ed. 34 (1995) 303.

[27] a. Y. Nicolas, P. Blanchard, E. Levillain, M. Allain, N. Mercier, J. Roncali, Org. Lett. 6 (2004) 273 ;

b. X. Sun, Y. Liu, S. Chen, W. Qiu, G. Yu, Y. Ma, T. Qi, H. Zhang, X. Xu, D. Zhu, Adv. Funct. Mater. 16 (2006) 917;

c. N. Kopidakis, W.J. Mitchell, J. Van de Lagemaat, D.S. Ginley, G. Rumbles, S.E. Shaheen, W.L. Rance, Appl. Phys. Lett. 89 (2006) 103524.

[28] A. Bilge, A. Zen, M. Forster, H. Li, F. Galbrecht, B.S. Nehls, T. Farrell, D. Neher, U.J. Scherf, Mater. Chem. 16 (2006) 3177.

[29] a. M. Ammann, A. Rang, C.A. Schalley, P. Bäuerle, Eur. J. Org. Chem. (2006) 1940;

b. P. Bäuerle, M. Ammann, M. Wilde, G. Götz, E. Mena-Osteritz, A. Rang, C.A. Schalley, Angew. Chem. Int. Ed. 46 (2007) 363.

[30] W.B. Jennings, B.M. Farrell, J.F Malone, Acc. Chem. Res. 34 (2001) 885.

[31] a. D. Seidel, V. Lynch, J.L. Sessler, Angew. Chem. Int. Ed. 41 (2002) 1422; 
b. T. Köhler, D. Seidel, V. Lynch, F.O. Arp, Z. Ou, K.M. Kadish, J.L. Sessler, J. Am. Chem. Soc. 125 (2003) 6872;

c. A. Gorski, T. Koehler, D. Seidel, J.T. Lee, G. Orzanowska, J.L. Sessler, J. Waluk, Chem. Eur. J. 11 (2005) 4179.

[32] a. S. Huang, L.-Y. Zou, A.-M. Ren, J.-F. Guo, X.-T. Liu, J. K. Feng, New. J. Chem. 36 (2012) 947;

b. S. Huang, A.-M. Ren, L.-Y. Zou, Y. Zhao, J.-F. Guo, J.-K. Feng, J. Mol. Model. 18 (2012) 393.

[33] P. Flores, P. Guadarrama, E. Ramos, S. Fomine, J. Phys. Chem. A 112 (2008) 3996.

[34] M. Garcia, E. Ramos, P. Guadarrama, S. Fomine, J. Phys. Chem. A 113 (2009) 2953.

[ 35] a. S. S. Zade, M.Bendikov, J. Org. Chem. 71 (2006) 2972;

b. L.Pandey, C. Risko, J.E. Norton, J.L. Brédas, Macromolecules, 45 (2012) 6405;

c. Y. Qiao, Z.Wei, C. Risko, H. Li, J.-L. Brédas, W. Xu, D. Zhu, J. Mater. Chem. 22 (2012) 1313.

[36] a. A.K. Bakhshi, J. Mol. Struct. ( Theochem) 209 (1990) 177;

b. A.K. Bakhshi, H. Ago, K. Yoshizawa, K. Tanaka, T. Yamabe, J. Chem. Phys. 104 (1996) 14;

c. A.K. Bakhshi, Deepika, J. Mol. Struct. ( Theochem) 499 (2000) 105.

[37] H. Ammar-Aouchiche, S. Djennane-Bousmaha, A. Boucekkine, Synth. Met. 140 (2004) 127.

[38] a. W. Kohn, L.J. Sham, Phys. Rev. 140A (1965), 1133;

b. A.D. Becke, J. Chem. Phys. 98, (1993), 5648;

c. C. Lee, W. Yang, R.G. Parr, Phys. Rev. 37B (1988) 785.

[39] P.J. Stephens, F.J. Devlin, C.F. Chabalowski, M.J. Frisch, J. Phys. Chem. 98 (1994) 11623.

[40] Gaussian 09, Revision A.02,

M.J. Frisch, G.W. Trucks, H.B. Schlegel, G.E. Scuseria, M.A. Robb, J.R. Cheeseman, G. Scalmani, V. Barone, B. Mennucci, G.A. Petersson, H. Nakatsuji, M.Caricato, X. Li, H.P. Hratchian, A.F. Izmaylov, J. Bloino, G. Zheng, J.L. Sonnenberg, M. Hada, M. Ehara, K. Toyota, R. Fukuda, J. Hasegawa, M. Ishida, T. Nakajima, Y. Honda, O. Kitao, H. Nakai, T. Vreven, J.A. Montgomery, Jr., J.E. Peralta, F. Ogliaro, M. Bearpark, J.J. Heyd, E. Brothers, K.N. Kudin, V.N. Staroverov, R. Kobayashi, J. Normand, K. Raghavachari, A. Rendell, J. C. Burant, S.S. Iyengar, J. Tomasi, M. Cossi, N. Rega, J.M. Millam, M. Klene, J.E. Knox, J.B. 
Cross, V. Bakken, C. Adamo, J. Jaramillo, R. Gomperts, R.E. Stratmann, O. Yazyev, A.J. Austin, R. Cammi, C. Pomelli, J.W. Ochterski, R.L. Martin, K. Morokuma, V.G. Zakrzewski, G.A. Voth, P. Salvador, J.J. Dannenberg, S. Dapprich, A.D. Daniels, O. Farkas, J.B. Foresman, J.V. Ortiz, J. Cioslowski, D.J. Fox, Gaussian Inc., Wallingford CT, (2009).

[41] a. U. Salzner, J.B.Lagowski, P.G.Pickup, R.A Poirier, Synt. Metals, 96 (1998) 177;

b. U. Salzner, J.B.Lagowski, P.G.Pickup, R.A Poirier, J. Comp. Chem. 18 (1997) 1943;

c. U. Salzner, Synt. Metals, 101 (1999) 482;

d. U. Salzner, Synt. Metals, 119 (2001) 215.
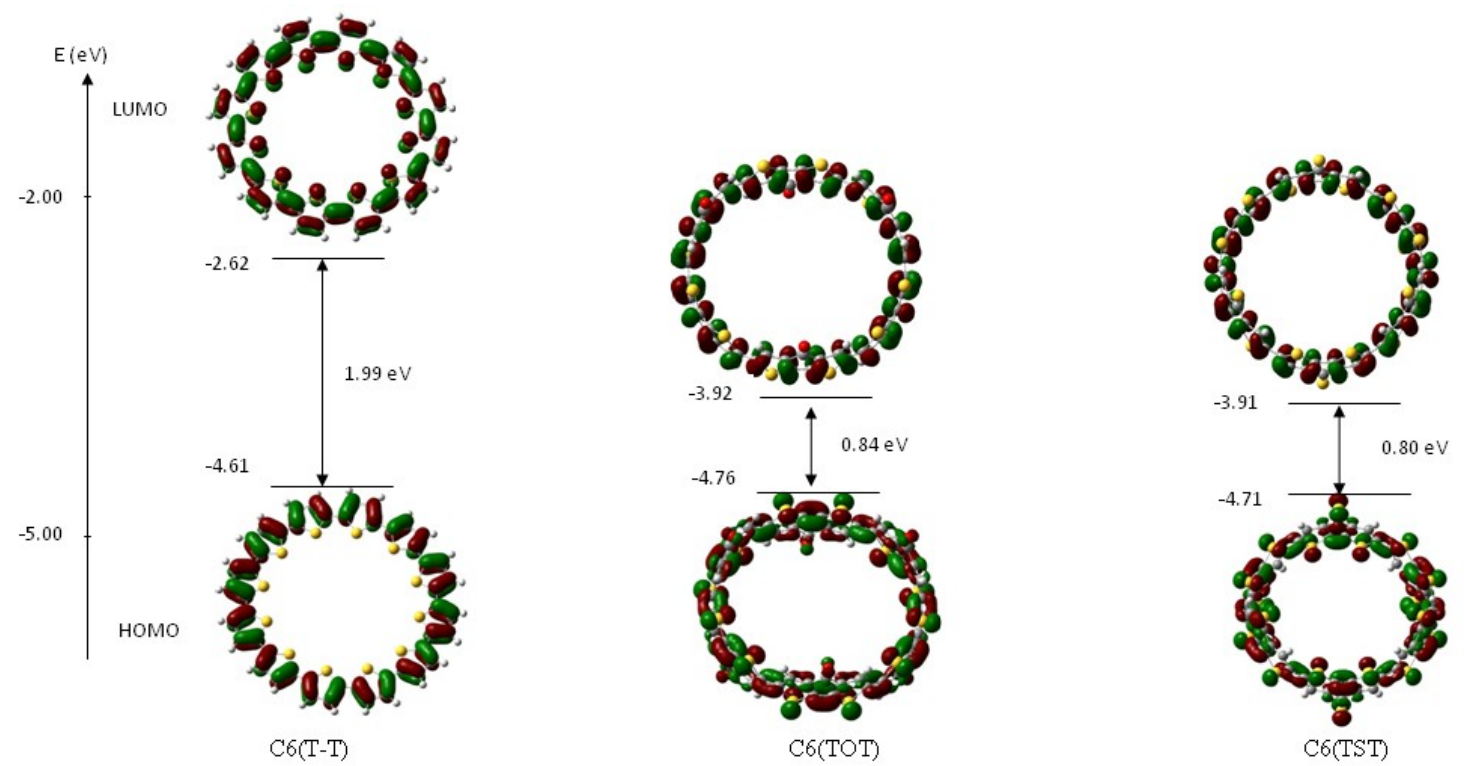

Fig. 2-1. Frontier orbitals of the unbridged $\mathrm{C} 6(\mathrm{~T}-\mathrm{T})$ and the bridged cyclo oligo(6) bithiophene $\mathrm{C} 6$ (TOT) and C6(TST) 


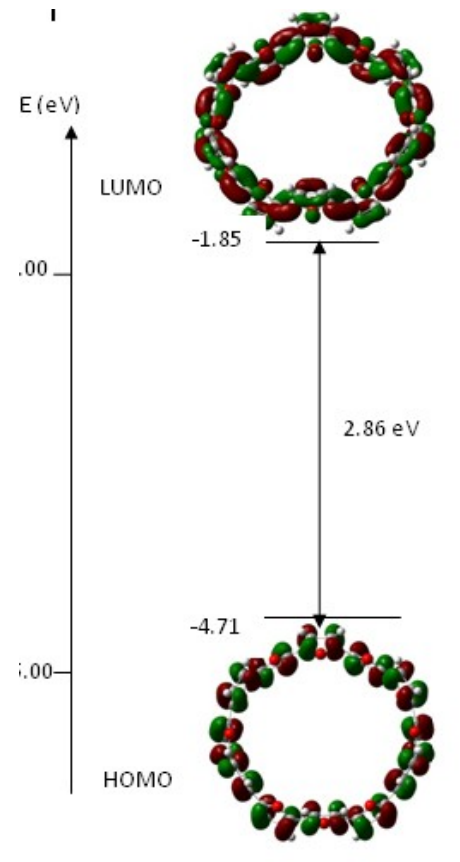

C6(F-F)

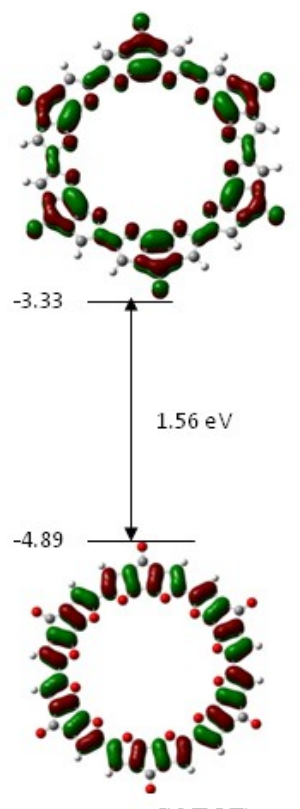

C6(FOF)

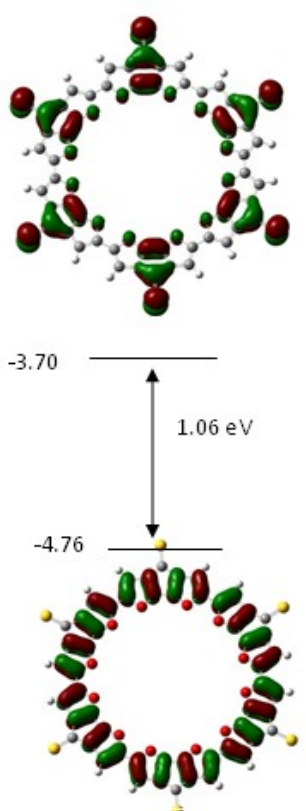

C6(FSF)

Fig. 2-2. Frontier orbitals of the unbridged $\mathrm{C} 6(\mathrm{~F}-\mathrm{F})$ and bridged cyclo oligo(6) bifuran $\mathrm{C} 6(\mathrm{~F} O \mathrm{~F})$ and $\mathrm{C} 6(\mathrm{FSF})$. 


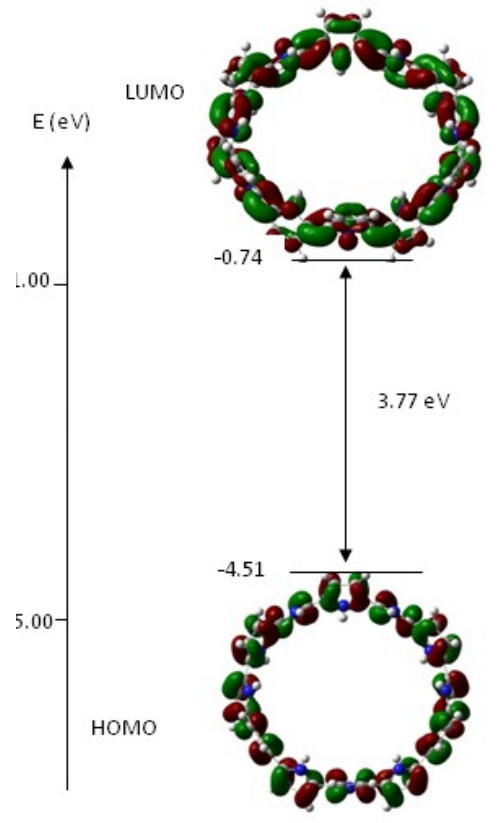

C6(P-P)

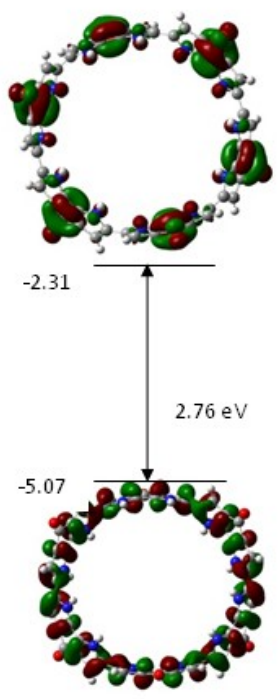

C6(POP)

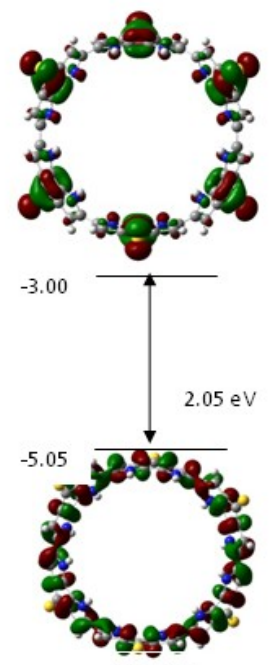

C6(PSP)

Fig. 2-3. Frontier orbitals of the unbridged $\mathrm{C} 6(\mathrm{P}-\mathrm{P})$ and the bridged cyclo oligo(6) bipyrrole $\mathrm{C} 6(\mathrm{POP})$ and $\mathrm{C} 6(\mathrm{PSP})$

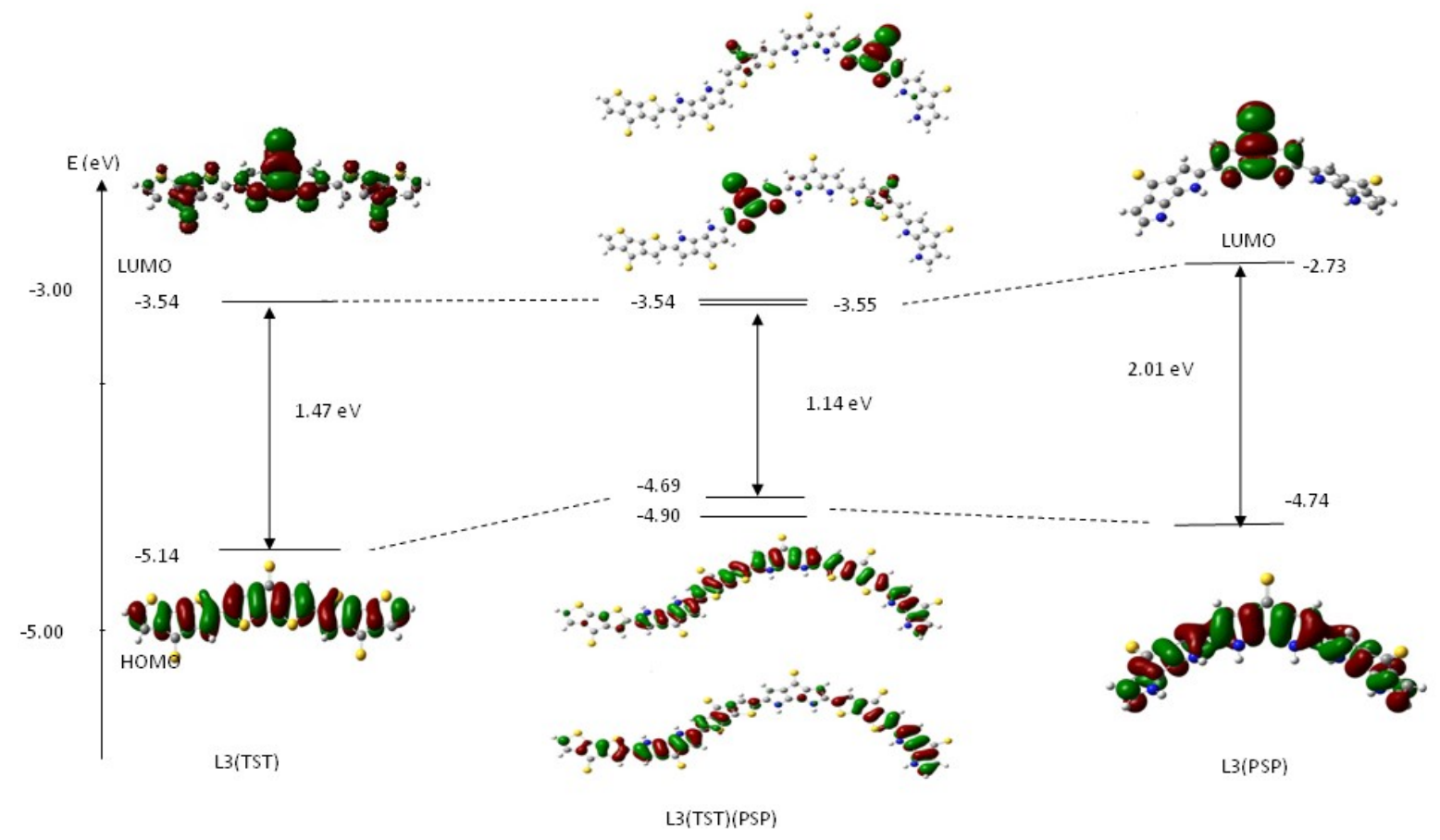

Figure 3-1. Frontier orbitals of the CS brigded co-oligo(3)(bithiophene-bipyrrole) L3((TST)(PSP)) in lin ear structures. 

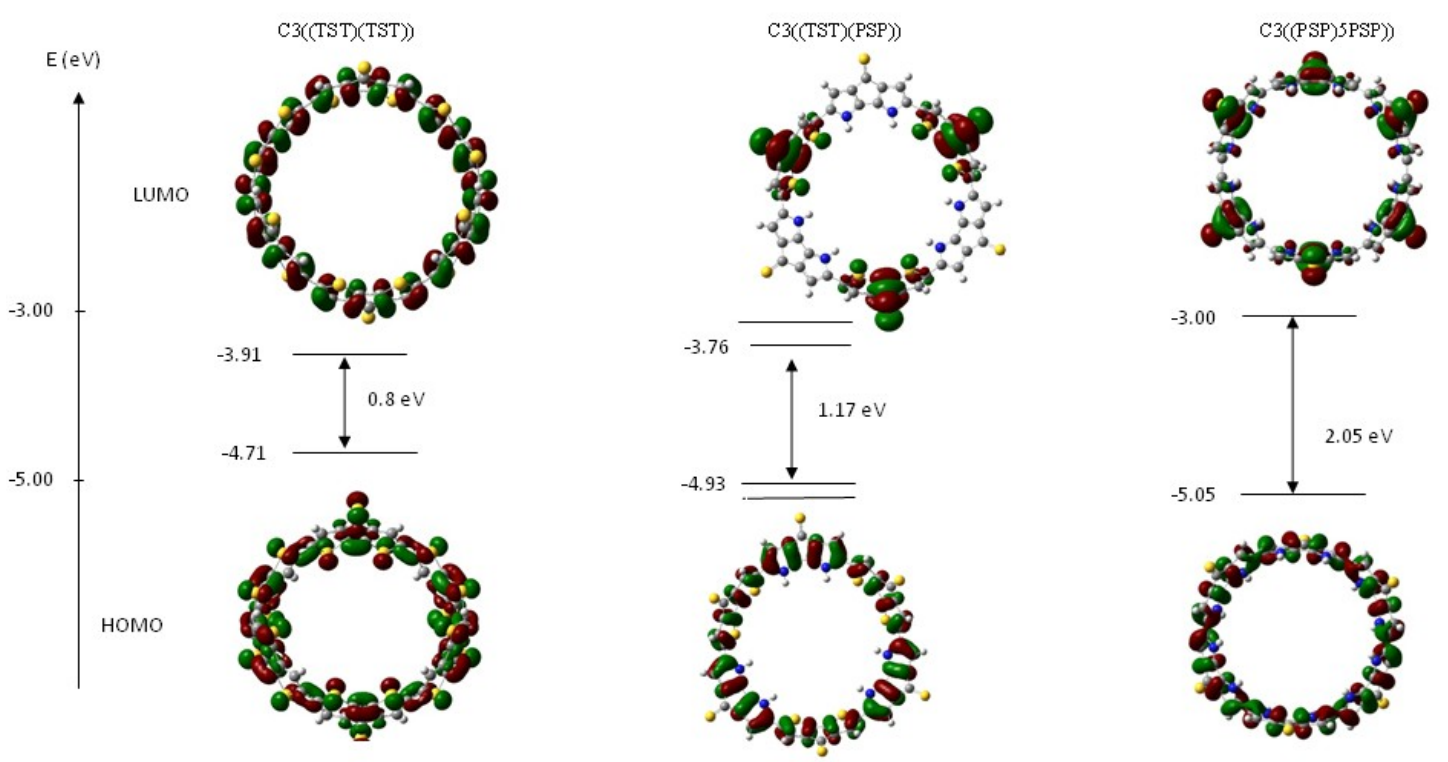

Figure 3-2. Frontier orbitals of the cyclo CS bridged co-oligo(3)(bithiophene-bipyrrole) C3((TST)(PSP)), of cyclo oligo(6) bithiophene C3((TST)(TST)), and of cyclo oligo(6) bipyrrole $\mathrm{C} 3((\mathrm{PSP})(\mathrm{PSP}))$.
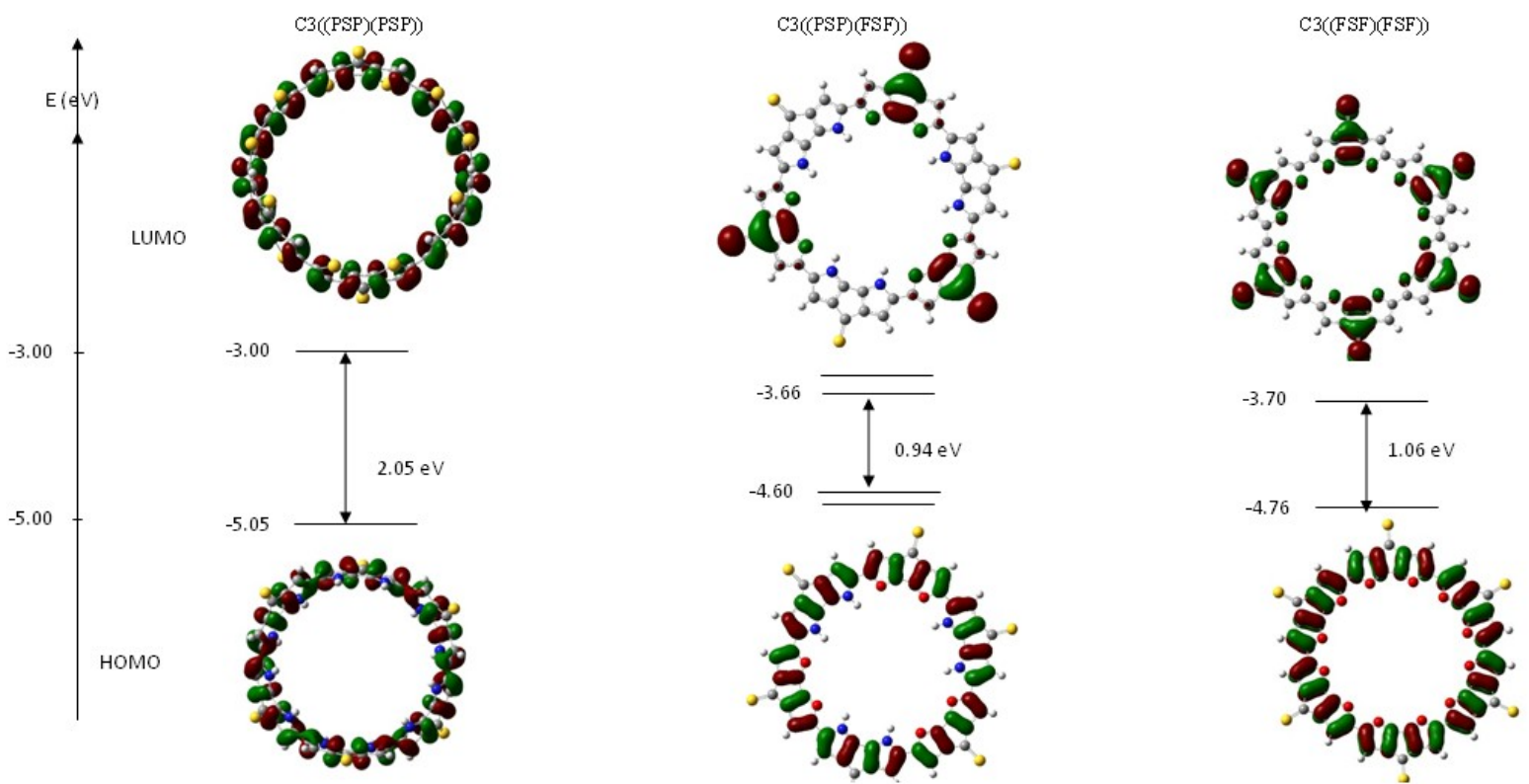

Figure 3-3. Frontier orbitals of the cyclo CS bridged co-oligo(3)(bifuran-bipyrrole), C3((FSF)(PSP)), of cyclo oligo(6)bifuran C3((TST)(TST)), and of cyclo oligo(6)bipyrrole C3((PSP)(PSP)). 